\title{
Wine analysis by 1D and 2D NMR spectroscopy*
}

\author{
I. Košir ${ }^{1}$, M. Kocjančič ${ }^{2}$ and J. Kidrič ${ }^{1, * *}$ \\ ${ }^{1}$ National Institute of Chemistry, Hajdrihova 19, SI-1000 Ljubljana, Slovenia \\ ${ }^{2}$ Agricultural Institute of Slovenija, Hacquetova 2, SI-1000 Ljubljana, Slovenia
}

\begin{abstract}
We have measured 1D and 2D ${ }^{1} \mathrm{H}$ and ${ }^{13} \mathrm{C}$ NMR spectra of selected Slovenian wines. Partial assignment of ${ }^{1} \mathrm{H}$ and ${ }^{13} \mathrm{C}$ resonances of alanine, valine, leucine, isoleucine, proline, threonine, ethanol, glycerol, butyleneglycol, and of acetic, tartaric, lactic, succinic, and malic acids in the wine samples was carried out by the combination of homo- and heteronuclear experiments COSY, HSQC and HMBC with known spectra of individual compounds. The spectra of wines of different variety, vintage and geographical areas differ mainly in the intensity of particular signals but also in the appearance of some signals which offers the possibility to follow the variability in their chemical composition on the ground of ${ }^{1} \mathrm{H}$ and ${ }^{13} \mathrm{C}$ signals.
\end{abstract}

Key words. Wine analysis - chemical composition - NMR spectroscopy - two dimensional experiments.

\section{Introduction}

Although limited by its relatively low sensitivity in comparison to other methods like IR or HPLC, NMR offers unique possibilities for the analysis of chemical composition of wines, for the detection of enrichment of musts by addition of sugars of different origin and for the identification of geographical origin. It is a non destructive technique capable of simultaneously detecting and determining a great number of organic compounds.

Currently ${ }^{1} \mathrm{H}$ and ${ }^{13} \mathrm{C}$ NMR spectroscopies are used for the detection of enrichment of musts by addition of sugars and for the identification of geographical origin [1,2]. It has been shown that ${ }^{13} \mathrm{C}$ NMR can successfully be used for detection of sugars, sugar alcohols and acids [3] and that ${ }^{13} \mathrm{C}$ resonances of amino acids can be used as fingerprints for the monitoring of European wines [4]. However, NMR spectroscopy has not yet been fully exploited in wine analysis.

The purpose of the present work is to examine further the capacity of $1 \mathrm{D}$ and $2 \mathrm{D}{ }^{1} \mathrm{H}$ and ${ }^{13} \mathrm{C}$ NMR experiments. We have examined eight samples of Slovenian wines that differ in geographical origin, vintage and variety but we present here as a token the results obtained with Sauvignon 1994, (Drava region), and White Pinot 1994, (Coastal region).
Slovenia, though small by surface, is pedologically and climatically very diverse and offers interesting possibilities for the study of influence of these factors upon the composition of wines of different variety, vintage and geographical areas.

Vineyards in the Drava region lie mostly on the grounds originating from soft carbonate rich soil. On the other hand the typical soil type in the Coastal region is a special type of terra rossa, which has a low content of carbonate soil. It is interesting to compare the climate of both regions. Average number of days during the year with the mean day temperature over $10^{\circ} \mathrm{C}$ is 185 in the Drava region and 218 in the Coastal region, the mean monthly temperature during the vegetation period from April $1^{\text {st }}$ till September $30^{\text {th }}$ is $16.2{ }^{\circ} \mathrm{C}$ in the Drava and $18.3{ }^{\circ} \mathrm{C}$ in the Coastal region. Intensity of rainfalls during the vegetation period is $580 \mathrm{~L}$ in the Drava and $742 \mathrm{~L}$ in the Coastal region and the average amount of sunny hours during the vegetation period is 1332.0 in the Drava and 1462.6 hours in the Coastal region.

All these variabilities cause differences in the chemical composition of wines from both regions. For example, the average contents of sugars and the total amounts of acids in must of Sauvignon from the Drava region differ from those in must of White Pinot from the Coastal region (Tab. I).

\footnotetext{
* Work presented at In Vino Analytica Scientia, Bordeaux, 12-14 June, 1997.

** Correspondence and reprints.

Received July 28, 1997; revised December 17, 1997; accepted December 23, 1997
} 


\section{Original articles}

Table I. The average contents of sugars and total amounts of acids for musts of Sauvignon from the Drava region and White Pinot from the Coastal region determined by the methods of O.I.V. (Office International de la Vigne et du Vin) in the period from 1973 till 1977 (by Ministry of Agriculture, Forestry and Food of the Republic Slovenia).

\begin{tabular}{lccc}
\hline Variety & Region & Sugars $(\%)$ & Acids $(g / L)$ \\
\hline Sauvignon & Drava & $15.0-17.0$ & $11.0-11.5$ \\
White Pinot & Coastal & $16.0-18.5$ & $8.0-10.0$ \\
\hline
\end{tabular}

\section{Materials and methods}

Sample preparation. Two $\mathrm{mL}$ of wine were freeze-dried, dissolved in $0.7 \mathrm{~mL}$ of deuterium oxide in $5 \mathrm{~mm}$ NMR tube. 3-(Trimethylsilyl)-1-propanesulfonic acid, sodium salt (DSS) served as an internal chemical shift standard. Temperature was $298 \mathrm{~K}$. pH of all samples was 3 .

Apparatus and measurements. The spectra were recorded on a Varian INOVA-600 NMR spectrometer operating at $600.1 \mathrm{MHz}$ for ${ }^{1} \mathrm{H}$ and $150.9 \mathrm{MHz}$ for ${ }^{13} \mathrm{C}$. For the onedimensional proton spectra 128 transients were accumulated with 40000 data points over a $4000 \mathrm{~Hz}$ bandwith. The measurement time was $22 \mathrm{~min} .{ }^{13} \mathrm{C}$ spectra were acquired with 29504 data points over a $32000 \mathrm{~Hz}$ bandwith with a $4.0 \mu \mathrm{s}$ $\left(45^{\circ}\right) \mathrm{rf}$ pulse. The number of transients was 24000 and the measurement time was $3 \mathrm{~h}$. The accuracy of ${ }^{1} \mathrm{H}$ chemical shift determination is $\pm 0.2 \mathrm{~Hz}$ and that of ${ }^{13} \mathrm{C}$ is $\pm 2.2 \mathrm{~Hz}$.

For two-dimensional COSY spectra [5] 16 scans with 4032 data points were acquired for each of the 512 increments. Measurement time was 3 h. 32 scans with 2048 data points were acquired for each of the 512 increments in twodimensional HSQC spectra [6] and acquisition time was $7 \mathrm{~h}$. The two-dimensional HMBC [7] spectra consisted of 4096 data points over a $7500 \mathrm{~Hz}$ bandwith. 104 scans were acquired for each of the 512 increments and the measurement time was $18 \mathrm{~h}$.

For the quantitative NMR measurements the method of standard addition was used to avoid problems with different matrix. A wine sample of Sauvignon 1994, (Drava region) and of White Pinot 1994, (Coastal region) was enriched with $2 \mathrm{~g} / \mathrm{L}$ of succinic acid and $1 \mathrm{~g} / \mathrm{L}$ of acetic acid. Measurements and processing of spectra of both original and enriched samples were carried out under the same conditions. Each sample was measured five times with 128 accumulations and delay was 5 times $T_{1}$. The relative standard deviation for signal intensities are \pm 0.09 for succinic and \pm 0.07 for acetic acid.

Determination of Organic Acids. A Hewlett Packard BioRad high-performance liquid chromatography (HPLC) system, equipped with an UV-VIS detector, was used for the analysis of organic acids. Individual organic acids were separated with a $300 \times 7.8 \mathrm{~mm}$ Aminex-HPX-87H column at $65^{\circ} \mathrm{C}$. Succinic acid was determined with a UV monitor at $210 \mathrm{~nm}$. The mobile phase was $0.007 \mathrm{M} \mathrm{H}_{2} \mathrm{SO}_{4}$ at $0.5 \mathrm{~mL} / \mathrm{min}$. Succinic acid (Fluka) was used as standard. Identification was based on the comparison of retention times with those of standard. Acetic acid (Merck) was determined under the instruction of EU [8].

\section{Results and discussion}

The ${ }^{1} \mathrm{H}$ and ${ }^{13} \mathrm{C}$ measurements of two samples of Slovenian wines Sauvignon 1994, (Drava region) and White Pinot 1994, (Coastal region), are representative of the adopted methodology and its potential of tracing differences in chemical composition. We have examined up to now eight more samples with similar success but we shall include the other results in a more extended study of Slovenian and geographically related wines.

${ }^{1} \mathrm{H}$ and ${ }^{13} \mathrm{C}$ resonances of alanine $(\mathrm{A})$, valine $(\mathrm{V})$, leucine $(\mathrm{L})$, isoleucine $(\mathrm{I})$, proline $(\mathrm{P})$, threonine $(\mathrm{T})$, ethanol $(\mathrm{EtOH})$, glycerol $(\mathrm{Gl})$, butyleneglycol $(\mathrm{Bgl})$, and of acetic (AA), tartaric (TA), lactic (LA), succinic (SA), and malic (MA) acids were assigned using homo- and heterocorrelation experiments described in the Materials and Methods section, in combination with the known spectra of individual compounds measured by us and compared with published data [9-12]. As a representative example the assignements of the spectra of Sauvignon, from the Drava region 1994, which contain the largest number of ${ }^{1} \mathrm{H}$ and ${ }^{13} \mathrm{C}$ signals, are given in table II. The carbonyl resonances of carboxylic acids are assigned using the HMBC experiment (Fig. 1). This $2 \mathrm{D}$ experiment allows for differentiation between ${ }^{13} \mathrm{C}$ chemical shifts of the two - COO groups of MA (Tab. II) which are in different chemical environment, in accordance with $1 \mathrm{D}{ }^{13} \mathrm{C}$ spectrum of individual $\mathrm{MA}$ in $\mathrm{D}_{2} \mathrm{O}$. In $1 \mathrm{D}{ }^{13} \mathrm{C}$ spectrum of wine sample the corresponding signals are not well resolved (Fig. 4). We note that at the experimental conditions adopted we were not able to observe the carbonyl resonances of aminoacids. However, this is not surprising since the concentration of amino acids in wine is much lower than that of any of the carboxylic acids.

Differences in ${ }^{1} \mathrm{H}$ and ${ }^{13} \mathrm{C}$ spectra (Figs. 2, 3, and 4) of Sauvignon 1994, (Drava region) and of White Pinot 1994, (Coastal region) are obvious by inspection. They are particularly pronounced in the carboxyl region 175-183 ppm in which we assigned -COO of SA, AA, LA, TA and MA.

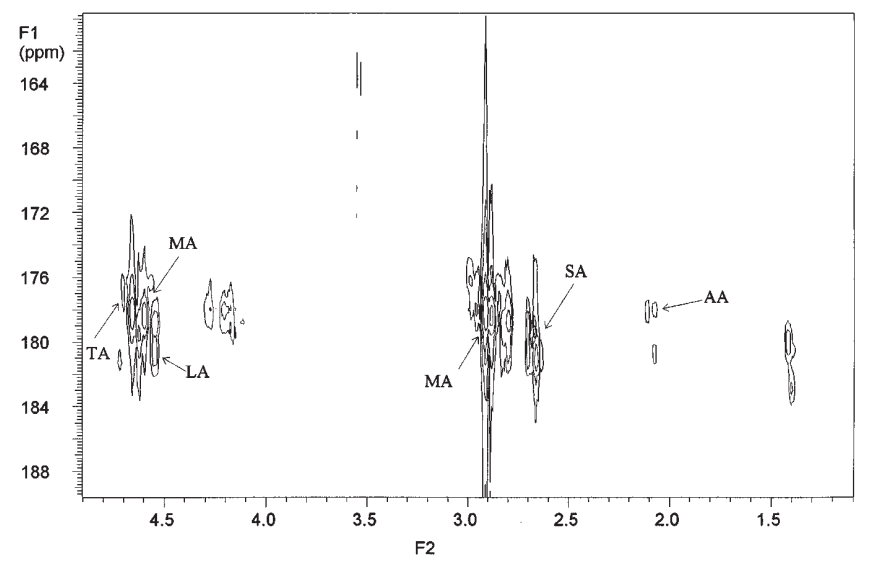

Fig. 1. Part of 2D HMBC spectrum of Sauvignon 1994, (Drava region) in the region of $-\mathrm{COO}$ of LA, SA, MA, AA, and TA. 

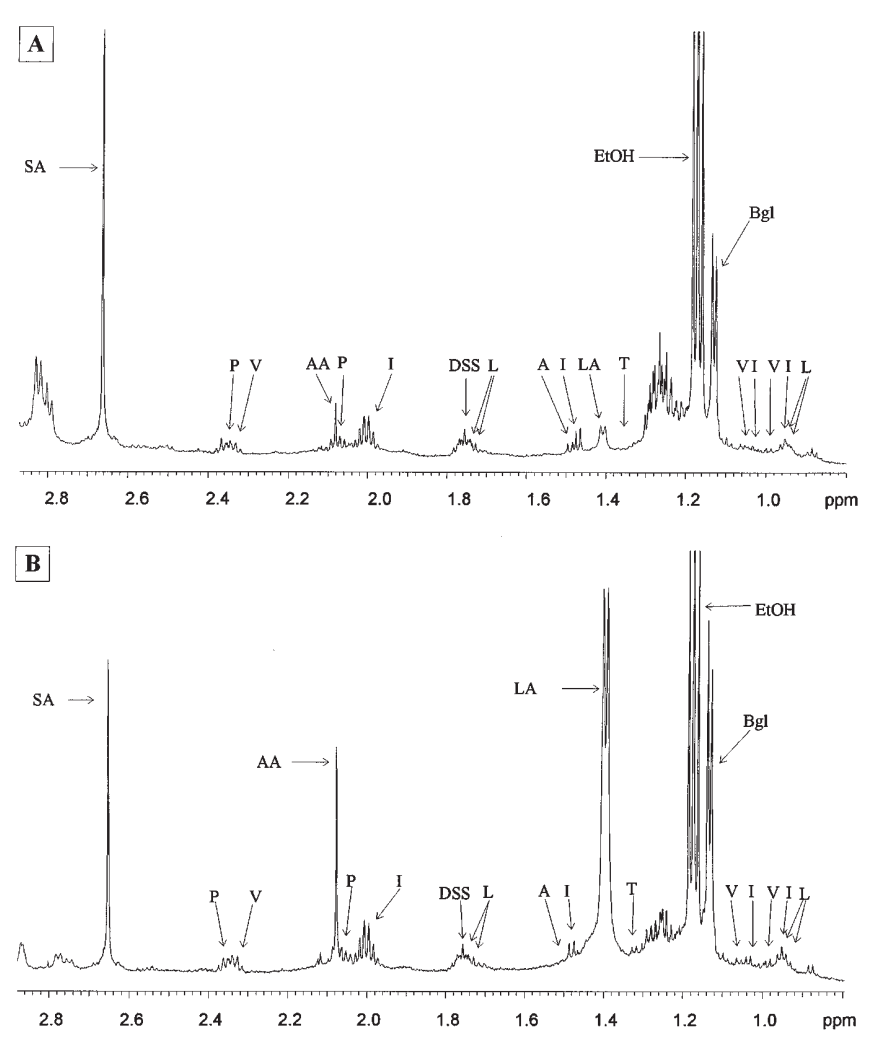

Fig. 2. Parts of ${ }^{1} \mathrm{H}$ one-dimensional spectra of two different wines: (A) Sauvignon 1994, (Drava region) and (B) White Pinot 1994, (Coastal region).
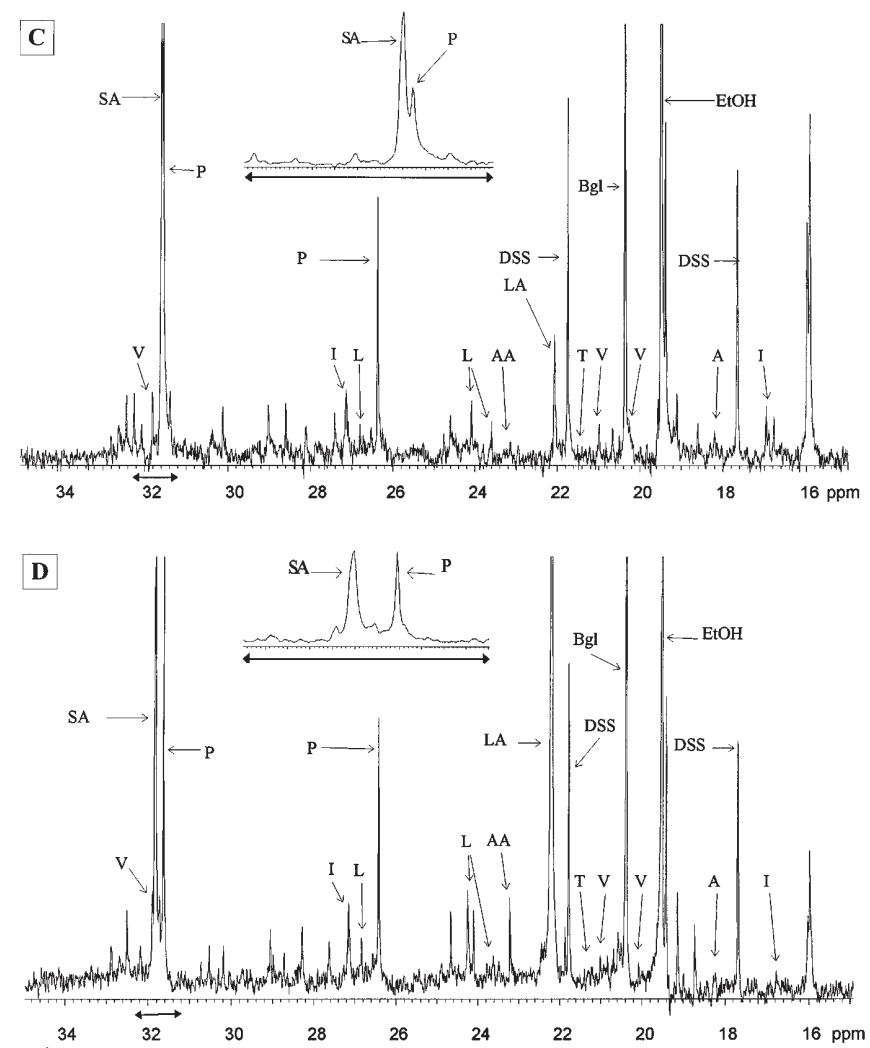

Fig. 3. Parts of ${ }^{13} \mathrm{C}$ one-dimensional spectra of two different wines: (C) Sauvignon 1994, (Drava region) and (D) White Pinot 1994, (Coastal region).

Table II. ${ }^{1} \mathrm{H}$ and ${ }^{13} \mathrm{C}$ chemical shifts (ppm) of compounds detected in the sample of Sauvignon 1994, (Drava region).

\begin{tabular}{|c|c|c|c|c|c|c|c|c|c|c|}
\hline \multirow[t]{2}{*}{ Compound } & \multicolumn{10}{|c|}{ Chemical shifts $\delta$ (ppm) } \\
\hline & $H 2$ & $C 2$ & $H 3$ & $C 3$ & $H 4$ & $C 4$ & H5 & $C 5$ & H6 & C6 \\
\hline A & 3.89 & 52.2 & 1.50 & 18.4 & - & - & - & - & - & - \\
\hline \multirow[t]{2}{*}{$\mathrm{V}$} & 3.69 & - & 2.33 & 31.7 & 0.99 & 20.9 & - & - & - & - \\
\hline & & & & & 1.04 & 20.2 & & & & \\
\hline \multirow[t]{2}{*}{$\mathrm{L}$} & 3.82 & 56.2 & 1.75 & 42.3 & 1.71 & 26.7 & 0.94 & 23.7 & - & - \\
\hline & & & & & & & 0.95 & 24.2 & & \\
\hline I & 3.77 & - & 2.00 & - & 1.47 & 27.1 & 0.95 & 13.5 & 1.01 & 16.8 \\
\hline $\mathrm{P}$ & 4.17 & 64.0 & 2.36 & 31.5 & 2.08 & 26.3 & 3.42 & 48.9 & - & - \\
\hline \multirow[t]{2}{*}{$\mathrm{T}$} & 3.71 & 60.9 & 4.27 & 68.9 & 1.37 & 21.4 & - & - & - & - \\
\hline & \multicolumn{2}{|c|}{$-\mathrm{COO}$} & \multicolumn{2}{|c|}{$-\mathrm{CH}$} & \multicolumn{2}{|c|}{$-\mathrm{CH}_{2}$} & \multicolumn{2}{|c|}{$-\mathrm{CH}_{3}$} & & \\
\hline AA & & 7.9 & - & - & - & - & 2.08 & 23.3 & & \\
\hline $\mathrm{TA}$ & & 6.5 & 4.77 & 74.8 & - & - & - & - & & \\
\hline LA & & & 4.44 & 69.7 & - & - & 1.42 & 21.8 & & \\
\hline SA & & 9.8 & - & - & 2.66 & 31.6 & - & - & & \\
\hline \multirow[t]{2}{*}{ MA } & & 8.0 & 4.61 & 69.9 & 2.90 & 41.3 & - & - & & \\
\hline & \multicolumn{2}{|c|}{178.2} & & & & & & & & \\
\hline $\mathrm{EtOH}$ & \multicolumn{2}{|c|}{-} & - & - & 3.67 & 60.0 & 1.17 & 19.4 & & \\
\hline Gl & \multicolumn{2}{|c|}{-} & 3.79 & 74.9 & 3.63 & 65.2 & - & - & & \\
\hline $\mathrm{Bgl}$ & \multicolumn{2}{|c|}{-} & 3.64 & 75.3 & - & - & 1.13 & 20.3 & & \\
\hline
\end{tabular}




\section{Original articles}
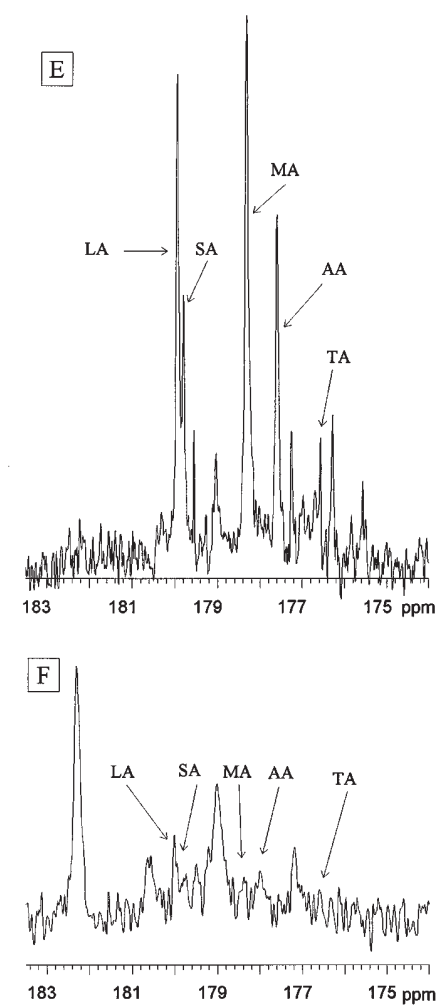

Fig. 4. Parts of ${ }^{13} \mathrm{C}$ one-dimensional spectra of two different wines: (E) Sauvignon 1994, (Drava region) and (F) White Pinot 1994, (Coastal region) in the region of -COO of LA, SA, MA, AA, and TA.

The corresponding signals in the spectra of White Pinot are much lower and somewhat broadened (Fig. 4). There also is a strong, at present unassigned, signal at $182.3 \mathrm{ppm}$, which is not found in the spectrum of Sauvignon. The differences also appear at 31-32 ppm (Fig. 3), where we found C3 of $\mathrm{P}$ and $-\mathrm{CH}_{2}$ of $\mathrm{SA}$, the signal of which is shifted to the low field for $0.2 \mathrm{ppm}$. We suppose that the origin of the line broadening and the shift of $-\mathrm{CH}_{2}$ signal may be the presence of the paramagnetic ions in White Pinot. This matter will be examined further on. There is one unassigned signal at 31.4 $\mathrm{ppm}$ in the spectrum of Sauvignon, not found in the spectrum of White Pinot.

In ${ }^{1} \mathrm{H}$ spectra of Sauvignon and White Pinot differences concerning the intensities of the signals belonging to $-\mathrm{CH}_{2}$ of $\mathrm{SA}$, to $-\mathrm{CH}_{3}$ of $\mathrm{AA}$ and to $-\mathrm{CH}_{3}$ of $\mathrm{LA}$ are notable (Fig. 2). Already from the inspection of the spectra it is seen that the signal of SA is more intense in the spectrum of Sauvignon while the intensities of the signals of AA and LA are smaller than the corresponding ones in the spectrum of White Pinot. The signal of LA is not suited for quantification (intensity measurements or integration) because it is a doublet and in the spectrum of White Pinot it is so intense that in the basis it covers the signal of $T$. The well resolved signals of SA and AA are more promising for intensity measurements and concentration determination. To evaluate the concentration of different compounds in the wine concentrate by using their signal intensities the following points should be considered. The line widths at half-height of the peak must be similar and as narrow as possible. The peaks used for the evaluation should have gone through their spinlattice relaxation time $\left(T_{1}\right)$ and thus be totally relaxed; this point has been checked for.

It is evident from table III that the agreement obtained between the concentration measured by NMR and that measured by HPLC for succinic acid is satisfactory while in the case of acetic acid the agreement is not so good. This is because acetic acid is a rather highly volatile and during the freeze-drying it is not possible to control all conditions. We are examining other ways of sample preparation in order to avoid this problem. The assignment of resonances of sugar compounds and the determination of the concentrations of different compounds in the examined wines are in progress.

Table III. Concentrations for succinic and acetic acid determined by NMR and HPLC in the sample of Sauvignon 1994, (Drava region) and in White Pinot 1994, (Coastal region).

\begin{tabular}{lcccc}
\hline Acid & $\begin{array}{c}\text { Concentration obtained } \\
\text { by NMR }(\mathrm{g} / \mathrm{L})\end{array}$ & \multicolumn{2}{c}{$\begin{array}{c}\text { Concentration obtained } \\
\text { by HPLC }(\mathrm{g} / \mathrm{L})\end{array}$} \\
& Sauvignon & White Pinot & Sauvignon & White Pinot \\
\hline $\begin{array}{l}\text { succinic } \\
\text { acetic }\end{array}$ & $1.2 \pm 0.1$ & $1.1 \pm 0.1$ & $1.08 \pm 0.03$ & $1.16 \pm 0.03$ \\
& $0.8 \pm 0.1$ & $4.1 \pm 0.4$ & $1.05 \pm 0.01$ & $3.56 \pm 0.03$ \\
\hline
\end{tabular}

\section{Conclusion}

In conclusion, the results of the present NMR analysis of selected Slovenian wines are promising. ${ }^{1} \mathrm{H}$ and ${ }^{13} \mathrm{C}$ spectra of Sauvignon 1994, (Drava region) and of White Pinot 1994, (Coastal region) reflect the differences in their composition and point to the discriminating potential of NMR methods. We hope that by preparing wine samples in different ways and by optimizing experimental conditions we can get more informations on wine composition and also to reduce the time necessary to perform 2D experiments. The NMR analysis will be extended to a larger selection of Slovenian wines of different variety, vintage and geographical areas.

\section{Acknowledgement}

We are grateful to Prof. D. Hadži for useful comments. This work was supported by the Ministries of Science and Technology, and of Agriculture, Forestry and Food of the Republic Slovenia.

\section{References}

1. Martin, G. J.; Guillou, C.; Martin, M. L.; Cabanis, M. T.; Tep, Y.; Aerny, J. J. Agric Food Chem. 1988, 36, 316-322.

2. Caer, V.; Trierweiler, M.; Martin, G. J.; Martin, M. L. Anal. Chem. 1991, 63, 2306-2313.

3. Rapp, A.; Spraul, M.; Humpfer, E.; Simultaneous Quantitative Determination of Many Compounds in Wine. In Vino Analytica Scientia, Bordeaux (France), Juin 1997; pp 359-365. 
4. Holland, M. V.; Bernreuther, A.; Reniero, F. In: Magnetic Resonance in Food Science, Belton, P. S.; Delgadillo; I.; Gil, A. M.; Webb, G. A. Eds. The Royal Society of Chemistry, Cambridge, 1995; Vol. 2, pp 136-145.

5. Rance, M.; Sorensen, O. W.; Bodenhausen, G.; Wagner, G.; Ernst R. R.; Wütrich, K. Biochem. Biophys. Res. Commun. 1983, 117, 479-485.

6. Wilker, W. Magn. Reson. Chem. 1993, 31, 287-292.

7. Müller, L. J. Am. Chem. Soc. 1979, 101, 4481-4484.

8. Official Journal of the European Communities, 1990, L 272.
9. Bhacca, N. S.; Hollis, D. P.; Johnson, L. F.; Pier, E. A.; Sholery, J. N. In: High Resolution NMR Spectra Catalog, Varian Associates, USA, 1963.

10. Johnson, L. F.; Jankowski, W. C. In: Carbon - 13 NMR Spectra: A collection of Assigned, Coded and Indexed Spectra, John Wiley \& Sons, New York, 1972.

11. Breitmaier, E.; Voelter, W. In: Carbon - 13 NMR Spectroscopy $3^{\text {rd }}$ ed., VCH, Weinheim, 1987.

12. Wütrich, K. In: NMR of Proteins and Nucleic Acids, John Wiley \& Sons, New York, 1986. 